\title{
Food portion sizes before and after bariatric surgery
}

\author{
S. Afshar ${ }^{1,2}$, S. Kelly ${ }^{2}$, K. Seymour ${ }^{2}$, S. Woodcock ${ }^{2}$ and J.C. Mathers ${ }^{1}$ \\ ${ }^{1}$ Human Nutrition Research Centre, Newcastle University, Newcastle upon Tyne, NE4 5PL and ${ }^{2}$ Department of \\ Surgery, North Tyneside General Hospital, North Shields, NE29 8NH
}

Bariatric surgery is a recommended treatment for individuals with a BMI of $40 \mathrm{~kg} / \mathrm{m}^{2}$ or more, or between $35 \mathrm{~kg} / \mathrm{m}^{2}$ and $40 \mathrm{~kg} / \mathrm{m}^{2}$ if they also have significant disease (e.g. type 2 diabetes or high blood pressure) that could be improved with weight loss ${ }^{(1)}$. Whilst such surgery is highly effective in producing sustained weight loss, and is relatively safe, little is known about the behavioural consequences of such surgery with respect to food choices. As part of our ongoing study into the impact of obesity and surgically induced weight loss on colorectal cancer risk (ISRCTN95459522), we conducted an interview estimating portion sizes of ten commonly consumed foods using a photographic food atlas ${ }^{(2)}$, before and 6 months post-bariatric surgery.

Twenty five participants who had completed 6 month follow-up were included in this analysis. Mean age at surgery was 46 years and the majority were female $(80 \%)$. Roux-en-Y gastric bypass was the most common type of surgery (17 patients) with 6 patients receiving sleeve gastrectomy and 2 gastric balloons. Baseline BMI was $42.1 \mathrm{~kg} / \mathrm{m}^{2}$ (SD 5.9) and this decreased to $32 \cdot 2 \mathrm{~kg} / \mathrm{m}^{2}(\mathrm{SD} 5 \cdot 7$ ) at 6 months.

\begin{tabular}{|c|c|c|c|c|}
\hline & \multicolumn{2}{|c|}{ Before bariatric surgery } & \multicolumn{2}{|c|}{ At 6 months after bariatric surgery } \\
\hline & Mean & SD & Mean & SD \\
\hline Bread & $61 \cdot 1$ & 31.7 & $27 \cdot 5^{*}$ & 18.8 \\
\hline Cheese & 38.5 & 28.5 & $19 \cdot 9 *$ & $16 \cdot 8$ \\
\hline Bananas & $93 \cdot 2$ & $50 \cdot 1$ & $63 \cdot 2 *$ & $29 \cdot 7$ \\
\hline Pasta & 194.6 & $95 \cdot 0$ & $69.6^{*}$ & 39.5 \\
\hline Milk & $93 \cdot 0$ & 112.6 & $112 \cdot 0$ & $101 \cdot 3$ \\
\hline Sausages & $119 \cdot 4$ & $100 \cdot 4$ & $24 \cdot 2 *$ & $24 \cdot 1$ \\
\hline Sugar & 0.9 & $2 \cdot 4$ & 0.8 & $2 \cdot 0$ \\
\hline Crisps & 28.8 & 25.9 & $18 \cdot 0^{*}$ & 12.5 \\
\hline Butter & $6 \cdot 5$ & 4.7 & $4 \cdot 0^{*}$ & $2 \cdot 8$ \\
\hline Pizza & 198.4 & $154 \cdot 8$ & $70 \cdot 1$ * & 67.9 \\
\hline
\end{tabular}

Values are mean estimated portion weights in grams. Mean values significantly different at 6 months after bariatric surgery (paired sample t-test): $* \mathrm{P}<0.05$.

Portion sizes for all foods, except for milk and sugar, were significantly $(\mathrm{P}<0.05)$ reduced after bariatric surgery with particularly large reductions in portion sizes of sausages, bread, pasta and pizza. In addition to contributing to reduced energy intake, changes in portion sizes of foods such as sausages and pizza may enhance the metabolic benefits observed following weight-loss surgery.

1. NICE clinical guideline 189 (2014) guidance.nice.org.uk/cg189.

2. Nelson M, Atkinson M \& Meyer J (1997) A Photographic Atlas of Food Portion Sizes. London: MAFF Publications. 